\title{
A Community of Educators Using Online Self-Organization to Develop a Process for Creating Technology-Integrated Instructional Materials
}

\author{
Elizabeth Wellman, Ed.D., Maya Creedman, Jana Flores \\ Center X, GSE\&IS, 2030 Moore Hall, UCLA, Los Angeles, CA 90095 \\ Tel: 310.206.2969 Fax: 310.206.5369 \\ Email: ewellman@ucla.edu; creedman@ucla.edu; jsflores@ucla.edu
}

\begin{abstract}
The Executive Office of the California History-Social Science Project and the Technology Projects office of Center X at UCLA have developed a project in which statewide history teachers form an online, self generating, problem solving community for the purposes of rewriting existing history and social science curricula for the integration of technology to support student historical thinking and understanding. Participants focus on collaboration and the problem solving process of instructional design in an online (Nexus) collaborative environment. The end product for the participants are several units of practice which reflect historical thinking and understanding and the use of technology to support those processes.
\end{abstract}

Keywords: distributed learning environments, learning communities, professional development, technology planning.

\section{Background and Project}

Traditionally, K-12 teachers are expected to develop instructional materials for their own classroom. Now, teachers often have the additional responsibility of integrating technology into their instruction. However, the integration of technology into current curricula is-non-trivial (Starr, 1996). The existing instructional methodology must be re-evaluated and adapted to take advantage of the technology. With little to no training or experience, most teachers are inadequately prepared to develop technology-integrated instructional materials. We are proposing that a community of educators use technology to form a distributed network to develop a process for the creation of instructional materials which integrate technology and to actually develop the materials. Essentially, these educators will engage in distributed cognition for the purposes of collective problem solving, the problems being the development of the process and the product. The educators will be bringing diverse understandings and expertise to the community. However, this community is self-organizational in nature. Solutions to the problems can be found despite conflicting information being brought to the system.

Beyond Primary Sources: Using Technology in the K-12 History-Social Science Classroom is a project conducted jointly by the California History-Social Science Project (CH-SSP) and the Office of Technology Projects in Center X at UCLA. This project provides K-12 teachers with the opportunity to collaborate on the development of instructional materials using technology to support historical thinking and understanding in K-12 students. Teachers will develop a process for developing these materials and then apply that process to actually develop instructional materials. This professional development project advances the professional development approach the California Subject Matter Projects at UCLA. First, a major part of the activity takes place online. Research suggests that participating in electronic networks is the most effective tool for training new teachers in using technology (OTA, 1996). Teacher to teacher online communication may encourage knowledgeable teachers to positively affect other teachers' attitudes and behaviors about using computers in the classroom (Becker, 1994). Additionally, it provides us with the advantage of including participants from geographically disparate areas.

\section{Community and Self-Organization}

The educator-driven approach distinguishes this project from previous professional development projects. We are interested in the educators developing their own processes, as a community. We discuss community in this paper as Phillip Agre (1995) defines it : "a web of associated relationships which form the basis of ongoing communication". This web creates a medium for distributed cognition. We are proposing that these teachers participate in distributed cognition as the mechanism for developing their process, as a community. 
Agre's (1995) communities run a continuum, from those run by a central leader who networks all the members, to those where all members assume the same role. This project uses the latter. Members do their own thinking, alone or with others, and then bring their thoughts back to the community. Motivating these educators is concern about their own situation. They perceive that this participation can help them to resolve a problem. As each individual's participation deepens, the process of participation is formalized. Agre argues that technology ("new media") supports distributed networked communities. This supports our choice to use a networked online environment for distributed cognition with our educators. The CH-SSP project creates community and establishes a network of distributed cognition using technology. The purposes are to develop processes for integrating technology into existing curricula, and for actually developing the curricula as a product. Essentially, these activities are collective problem solving. Proposed models for collective problem solving within a distributed system have focused on the concept of self-organization (Johnson, 1998).

\section{The Project, January, 2000}

The CH-SSP academy conducted a professional development workshop in Spring of 1999 and is running an academy in January of 2000. We are interested in taking our experience from the first workshop, and applying the models of community and self-organization to the January 2000 academy. There are two major activities - the development of the process and the development of the product. Each group will develop a process for designing technology integrated instruction for history-social sciences. This process will be represented as a flow chart with several nodes or decision points. All groups will bring their process to the community where the processes will be integrated to form a networked, nodal web. Individuals will then use the nodal web (the problem space) to make decisions about the process they as individuals are going to use to develop their materials. They will then develop their materials according to the process.

Most activities in this community take place online. Some activities also take place face-to-face, but this is only approximately $15 \%$ of the communication. The online environment will be used both synchronously and asynchronously. This will include discussion groups, chat rooms, posting of instructional materials, peer evaluation and editing of those instructional materials, sharing of resources, and sharing of instructional methodologies and experiences. Specifically, each group will have chat time and discussion groups as they find are necessary. Each group will post it's process, and the global community process will be posted. Each individual will post a draft of their instructional materials for peer review and post their final product. When all the final materials are posted, they and the process used to develop them, will be made available on the Internet.

\section{Conclusion}

The strength of approaching the development of a process and a product in this manner is the use of community and of a self-organizing system. The shared attributes of the individuals of the community -- their common activities and relationships -- provide a basis for distributed cognition. The attributes of self-organization provide diversity, which strengthens the communication and the optimization of decision making directed towards solving the problem. Finally, the decentralization of control, turning it over to the educators, eliminates the possibility of leadership imposed decisions. This combination of shared and diverse elements, without central control creates an environment where diverse possibilities are considered and optimal decisions can be made.

\section{Bibliography}

Agre, P.E. (1998). Designing genres for new media: Social, economic and political contexts. In Steve Jones (ed.) CyberSociety 2.0: Revisiting CMC and Community. Sage.

Becker, J. (1994). How exemplary computer-using teachers differ from other teachers: Implications for realizing the potential of computers in schools. Journal of Research on Computing in Education, 26 (3), 291-321.

Hughes, J. (1998, April). The road behind: How successful, technology-using teachers became successful. Paper presented at the meeting of the American Educational Research Association, San Diego, CA.

Johnson, N, (1998). Collective Problem Solving: Functionality beyond the Individual: LA-UR-98-2227.

Office of Technology Assessment. (1995). Teachers and technology: Making the connection (GPO stock \#052-00301409). Washington D.C.: Government Publishing Office.

Starr, P. (1996). Computing Our Way to Educational Reform. The American Prospect no. 27, July-August 1996. 